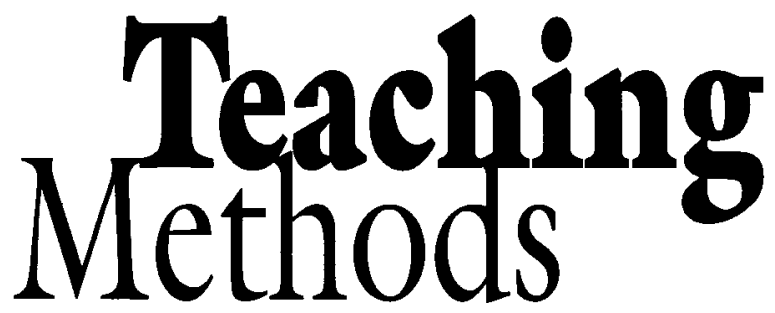

\section{A Low-cost Interactive Computer Program for Teaching Landscape Plant Materials}

\author{
Peter M. Shaw ${ }^{1}$
}

Additional index words. interactive computer program, HyperCard, hypermedia

Summary. A low-cost interactive computer program was designed to assist in teaching landscape plant material classes or any other class that could benefit from the use of computer graphics. The program was written in HyperCard to be used on any Macintosh computer. To illustrate the morphology and to assist in learning the terminology required to identify plants, a dichotomous keying system incorporating computer graphics was developed to lead the student through an interactive lesson. In the process of keying out plants, the student encounters the terminology associated with the groups of plants during the lesson. The student is introduced to plant groups, the terminology, and the concept of the classification process in one interactive lesson.

${ }^{1}$ Former Graduate Teaching Assistant, Department of Horticulture and Landscape Architecture. Washington State University, Pullman, WA 99164. Present address: Horticulture Instructor. Spokane Community College. N. 1810 Greene St. MS2080 Spokane, WA 99207-5399.
$\mathbf{P}$ lant material and other horticulture classes lend themselves well to graphically based, computerassisted instruction. Using interactive computerized lessons, students can progress at their own speed and to any level for effective inquiry and discovery learning. The depth of the lesson is limited only by the available applications, available data, and the expense of the computer hardware. In a recent review of the benefits of using interactive computers, White et al. (1990) described a system that included a network of satellite telecommunication systems, traveling lecturers, and the use of videodisc technology in horticulture. This videodisc system for horticulture education is very appealing, but major disadvantages to such a system include the cost of the hardware and the limited software available. A low-cost interactive system using well-established hardware and inexpensive software is presented as an alternative.

In addition to plant identification and usage in the landscape, plant material classes are used to teach students the varied terminology used to describe such things as leaf shapes, margins, bases, cone or flower characteristics, and fruit types. A student who is proficient in the terminology has the ability to read written descriptions in textbooks and have some confidence in being able to identify a plant correctly. One instructional method used in plant material classes is to expose students to a list of terms such as those in Dirr's Manual of Woody Landscape Plants (1990) or Harrington and Durrell's How to Identify Plants (1957), and then to require rote memorization. Afterwards these terms are applied to the field. The difficulty with such a system is that students don't really "see" the terms.

Another goal of plant material classes is for students to begin to see some morphological relationships among groups of plants and to understand how morphology can be useful in identification ofunknown species or in the plant selection process. The computer can assist the instructor and student in satisfying all of these goals.

With technical assistance of Academic Computing Services at Washington State Univ., a project was initiated to design a computer program to assist in teaching plant material classes. This program can be run on a standard Macintosh computer without the additional hardware or software required for a videodisc system. The application was written in HyperCard and designed for the black-and-white screen of a Macintosh SE.

The goals of this program were to design a dichotomous keying system that would introduce students to the important terminology of a particular group of plants using a combination of text and graphics, create a keying system that helps students become familiar with the major groups of plants, and develop a computer-aided system that could be used in other disciplines to correctly identify any selected group of things, living or not.

To satisfy the primary goal, keys, called units, were constructed for groups of plants. To illustrate a unit, a key to selected species of conifers was constructed. Additional units might include conifer cones, broadleaf evergreens, or flower and fruit types. The unit was not designed to contain all conifers, nor did it attempt to identify all the conifers used in specific geographical locations or for specific use groups. The individual conifers were selected to show the important structures, parts, and relationships that make the group unique, and also to show the differences that delineate a family, genus, or species from others.

To show the relationships among pines, the key requires the user to read and to see that pine leaves are arranged in fascicles, and that leaf number may differ among species. Further delineation of the pines is by needle number and margin characteristics, sheath length and persistence, presence and type ofpubescence, or cone characteristics. Plant habit usually is not stressed, but was included. As a class exercise, a student could be given five or six care- 
fully selected unknowns and be required to identify each correctly. By doing so, the exercise will expose the student to the important morphological characteristics.

HyperCard is usually furnished with all Macintosh computers. The attributes of this program are that it is reasonably easy to script and very easy to use. It also integrates text and graphics very efficiently. HyperCard produces a "stack" of "cards"-the cards become the screen image. The dichotomous key consists of a base of 13 cards (a Decision Card, Graphic Card, Species Card, Genus Card, Quick Species Card, two Compare Species Cards, four Help Cards, and two Glossary Cards). Using the mouse, a user can move forward, backward, compare two species, look ahead, or jump to a Species Card if the identification is known.

The backbone of the key is the Decision Card, which is divided into an upper and a lower half (Fig. 1). There is a box for text containing the paired contrasting statements. The check mark is a button, which, when clicked with the mouse, directs the computer to the next Decision Card or to a Species Card. The magnifying glass is another button that, when chosen, directs the computer to show a graphical example of the contrasting statements. During assemblage of the keys, graphics from the Graphic Card can be shrunk and pasted to the right of the check mark, eliminating the need for the magnifying glass.

Other buttons on the decision card include the Step Back Button, which enables the user to go back in the order in which the cards came, one card at a time. This feature is very helpful should the user have made an error in direction. A Start Over/Quit Button allows the user to quit or to start over from anywhere in the program. A Species List Button has two functions. First, it gives the user the ability to see all the species in the key. Second, should the user know the identification and want to read a complete botanical description, clicking on the button brings up a scrolling box. The user simply selects a species name and the Species Card appears. Glossary Aid and Glossary List Buttons are also present and will be discussed in greater detail later. Every attempt was made to keep similar buttons in the same locations on the different cards for ease of use and to

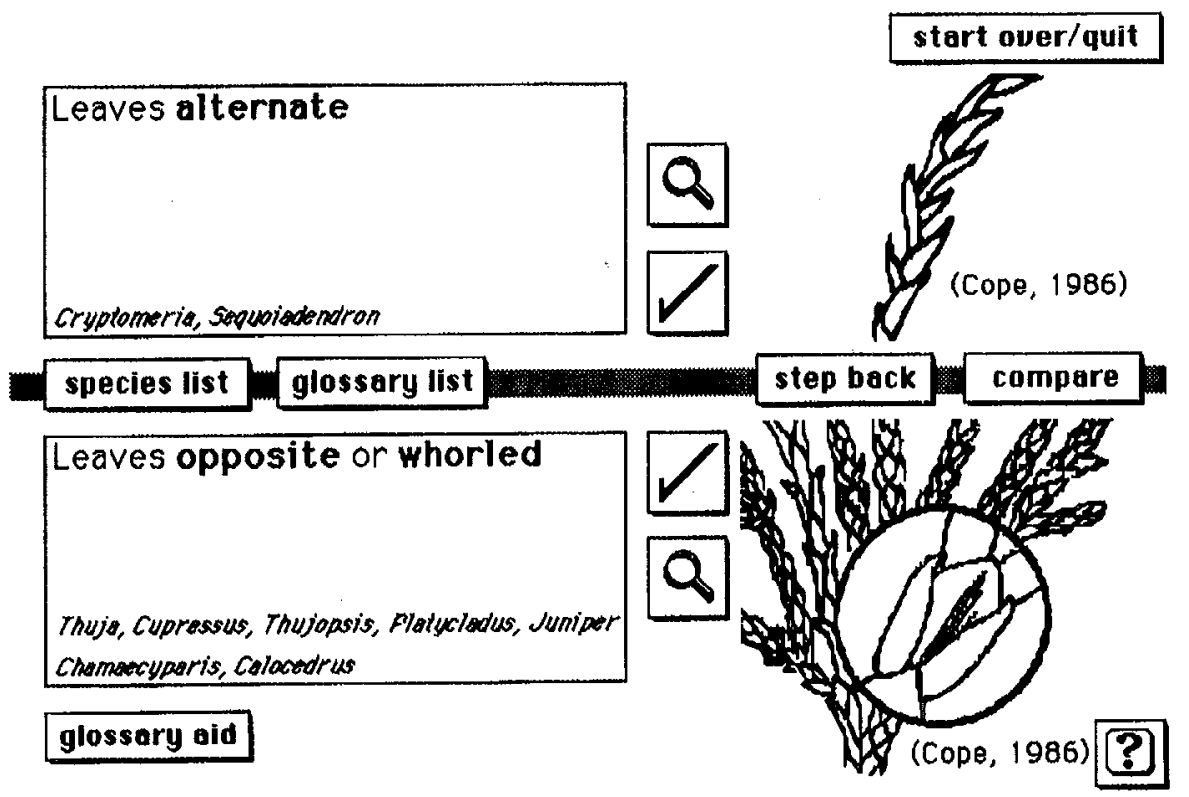

Fig. 1. A Decision Card in the dichotomous key stack illustrating the card layout and buttons. minimize mouse movement.

The graphics are contained on Graphic Cards and can be black-andwhite or color images (Fig. 2). Aside from the increased cost and expense in memory, black-and-white line drawings have other advantages over color photographs. Line drawings can be used to show the details by exaggerating the specific site while leaving out the background "noise" often seen in photographs. Keeping copyright laws in mind, graphics can be captured and copied to Graphic Cards using a flatbed scanner and scanner software. An Apple scanner and HyperScan give fast and excellent results for use in HyperCard. Additional manipulation of the graphics is possible using one of the available paint or image-processing programs.

The glossary can be accessed from the Decision Card in two ways (Fig. 1). First, by using the mouse arrow to point to a word on the screen, the user simply clicks on a word and, if that term is in the glossary, the Glossary Card will appear (Fig. 3). The Glossary Card is divided into two halves. One half contains a written description and the other contains the corresponding

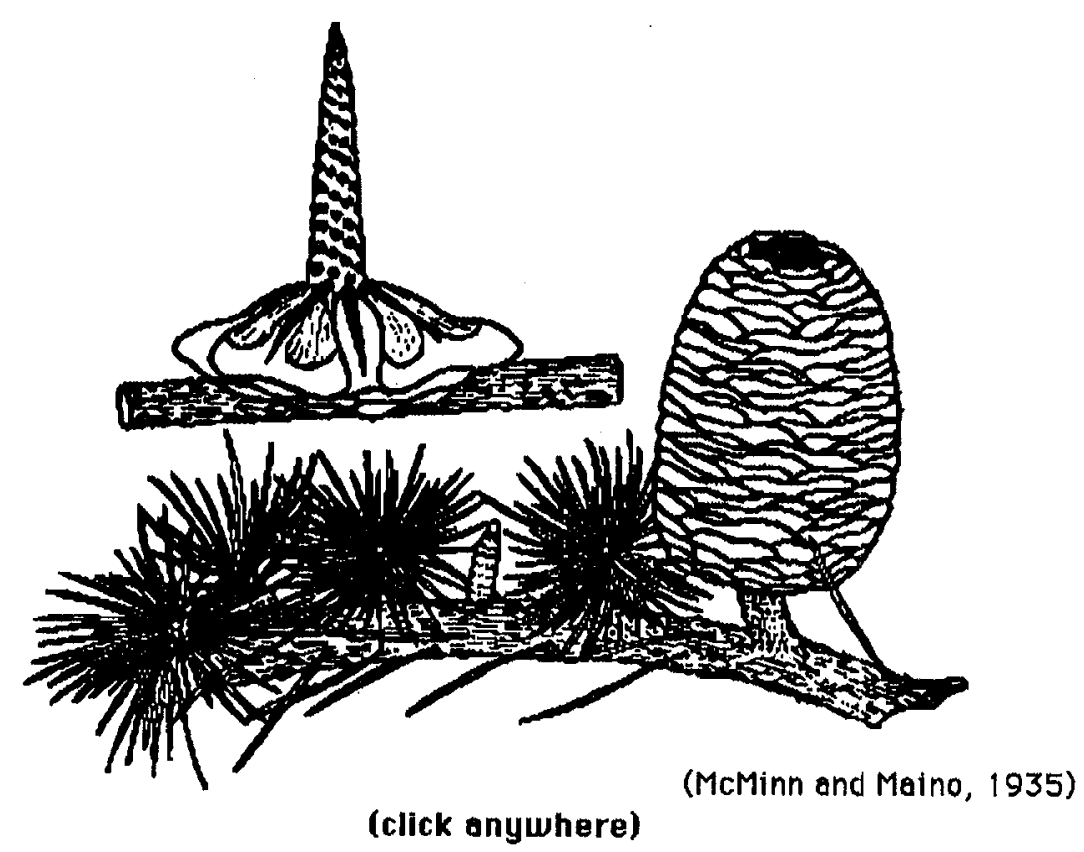

Fig. 2. Graphics can be captured and copied to HyperCard graphic cards using a flatbed scanner and scanner software. 


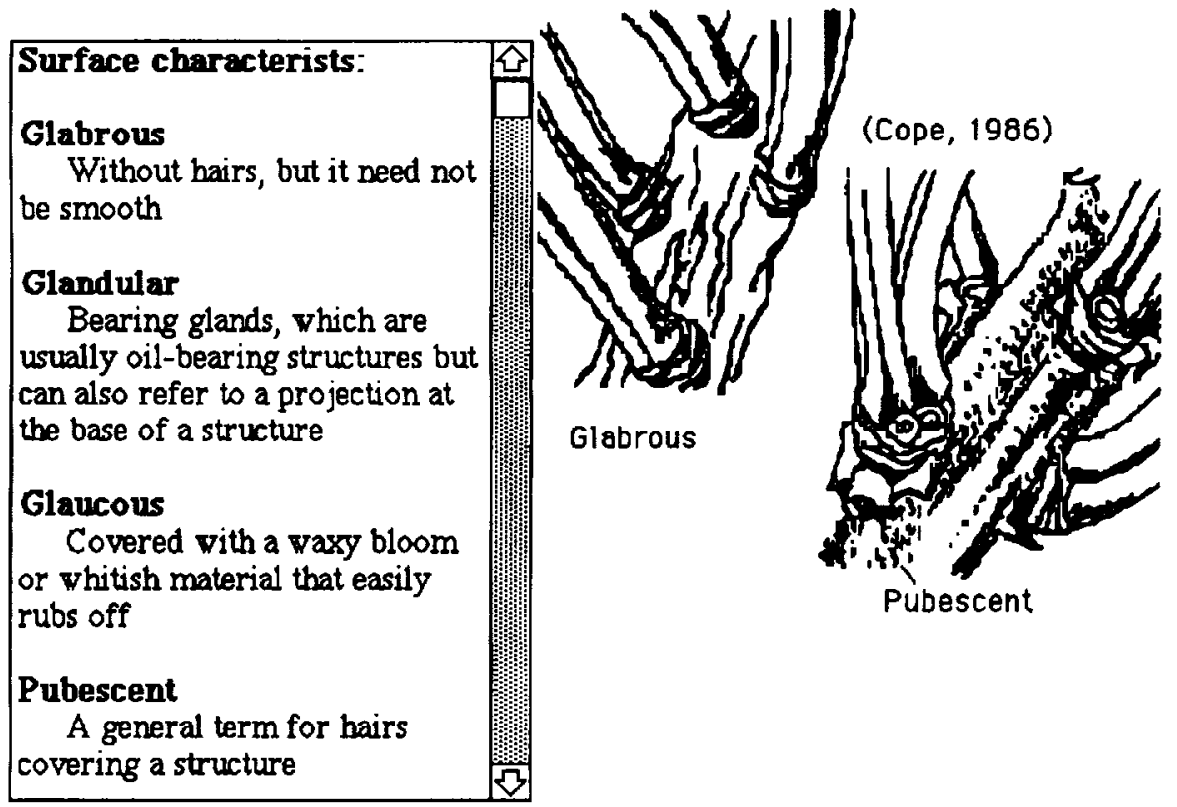

Fig. 3. The Glossary Card is divided into two halves, with text on one half and graphics on the otber. graphics image. Second, the Glossary Card may be accessed by clicking on the Glossary List Button and selecting a term from the scrolling box.

After progressing through the key, a Species Card appears (Fig. 4). The Species Card contains the name (botanical and common) of the plant, a scrolling field for text (complete description), two Magnifying Glass Buttons for full-screen graphics, and room for manipulated graphics in the lower half of the card. The Species Card also contains the Step Back, the Start Over/Quit, and the Compare Species buttons.
The Quick Species Card contains all of the available plant names in a scrolling box. The user simply scrolls the box to locate the desired species, and points to the line containing the name and then clicks. The computer displays the desired Species Card. If the user is not quite sure that the plant specimen is the same as the plant displayed on the screen, the user can compare it to another plant by using the Compare Button.

The Compare Button allows the student to compare, on the same screen, two species. There are two scrolling

\section{Pinus densiflora}

\begin{tabular}{|l|}
\hline F. densiflare Siebold \& Zuccarini \\
Japanese red pine \\
Tree to $20 \mathrm{~m}$, to $30 \mathrm{~m}$ in Jepan. Crown conic \\
in young trees, becoming wide-spreading and \\
flat-topped in older ones. Bark reddish \\
brown, scoly, fissured and greyish at bese. \\
Shoot whitish green, later pink-brown. Bud
\end{tabular}

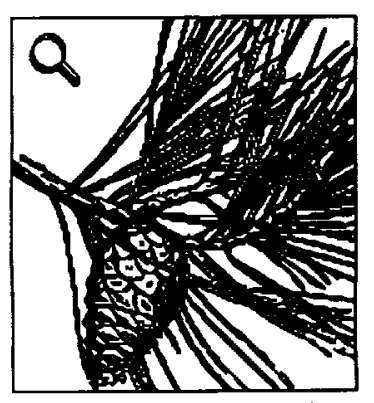

(Belley, 1948)

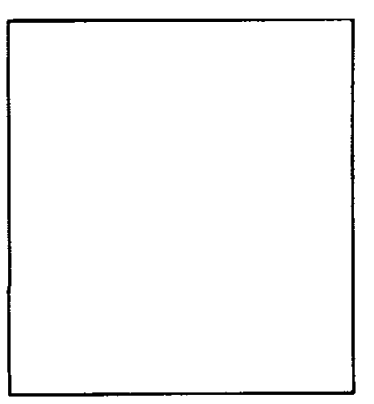

step back

compare
Fig. 4. An example of a Species Card illustrating the graphics that can be accessed either by the magnifying glass or those that bave been modified using Adobe Photoshop. fields, each with all of the plant names. The user simply selects one species from the left box and one species from the right box. The result is another Compare Species Card. This card is similar to the Decision Card in that it is divided into two halves, each having a scrolling field and a Magnifying Glass Button to show the graphic. However, the upper half of the card contains one species and the lower half contains the other. The scrolling fields contain the exact description found on the scrolling field of the Species Card and one of the graphics from their respective Species Cards. The user can jump from one species graphic to another and compare descriptions without having to relocate individual Species Cards. The Return Button returns the user to the Compare launch point.

The second goal of the program was to expose students to groups of plants. This is achieved by using a Genus Card (Fig. 5). The card looks very much like a Species Card, but contains information on the genus. At the point in the key where pines are delimited, a Genus Card appears and shows the significant morphological features along with an area for written information. By clicking on the Check Mark Button, the student is returned to a Decision Card to finish keying out the pines.

The third goal of the key was to be able to adapt a system to any location or discipline necessary. Entomologists and mycologists use line drawings extensively to illustrate morphology. However, many references usually are required to have all the necessary drawings. This system could be used easily in either of these disciplines.

The program was tested in Jan. 1990 on two groups of 20 sophomore horticulture and landscape architecture students enrolled in plant material classes at Washington State Univ. A lesson plan similar to the one mentioned above was used to test the program. A few of the students had never used a computer, whereas most had never used HyperCard. The program proved very easy to use. Many students stayed after class to key-out additional plants. The only problem that arose with the program was that the Compare Species function worked only for the first user who selected plants. This problem occurred because the program was distributed to work stations 


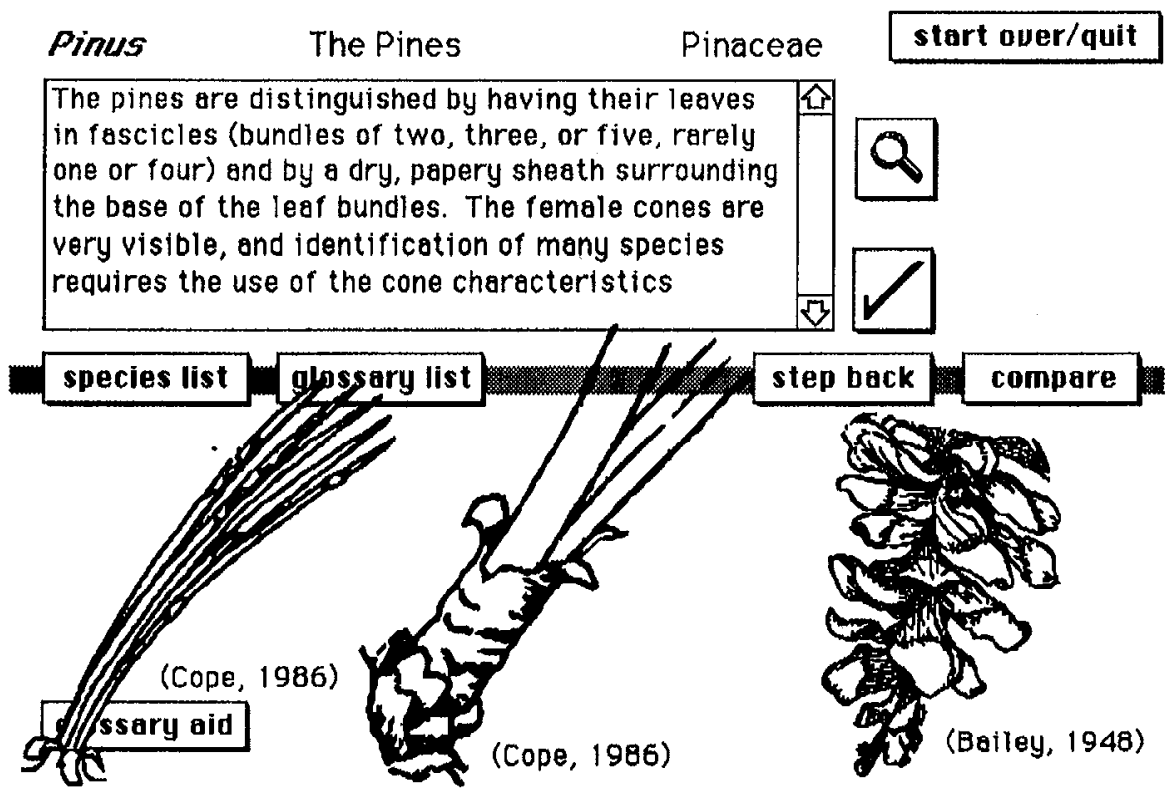

Fig. 5. An example of a Genus Card. This card can be used to stress the important morphological features that were used to arvive at this genus.

using a server, and HyperCard 2.1 is not networkable for read/write access. The other comments were related to how well the keys worked for the specimens being used, and the drawings used.

While videodisc technology may be the wave of the future in interactive computer programs, at present there is a need for low-cost systems using widely available hardware and software. A lowcost alternative that proves to be easy to use, effective, and entertaining to students could help bridge the time and money gap.

\section{Acknowledgement}

Brian Harvey and Judy Hart of Academic Computing Services deserve all of the credit for scripting this program and, without their sincere help in the overall design, this program would have only been a dream.

\section{Literature Cited}

Bailey, L.H. 1948. The cultivated conifers in North America. MacMillan,. New York.

Cope, E.A. 1986. Native and cultivated conifers of Northeastern North America. Cornell Univ. Press. Ithaca.

Dirr, M.A. 1990. Manual of woody landscape plants: Their identification, ornamental characteristics, culture, propagation and uses. Stipes, Champaign, Ill.

Harrington, H.D. and L.W. Durrell. 1957. How to identify plants. Swallow, Chicago.

McMinn, H.E. and E. Maino. 1935. Pacific coast trees. Univ. of Calif. Press, London.

White, J.W., D.J. Beattie, and P. Kubek. 1990. Inquiry learning with videodiscs and computers: aninnovative teaching method for horticulture courses. HortScience $25: 385-388$. 